\title{
Carvacrol and Thymol for Fresh Food Packaging
}

\section{Marina Ramos ${ }^{1}$, Ana Beltran ${ }^{1}$, Arancha Valdes ${ }^{1}$, Mercedes A Peltzer ${ }^{1}$, Alfonso Jimenez ${ }^{1}$, María C Garrigos ${ }^{1}$ and Gennady E Zaikov}

${ }^{1}$ Analytical Chemistry, Nutrition \& Food Sciences Department, University of Alicante, P.O. Box 99, 03080, Alicante, Spain

${ }^{2}$ N.M. Emanuel Institute of Biochemical Physics, Russian Academy of Sciences, 4 Kosygin str. Moscow 119334, Russia

\begin{abstract}
Active packaging is becoming an emerging food technology to improve quality and safety of food products. One of the most common approaches is based on the release of antioxidant/antimicrobial compounds from the packaging material. In this work an antifungal active packaging system based on the release of carvacrol and thymol was optimized to increase the post-harvest shelf life of fresh strawberries and bread during storage. Thermal properties of the developed packaging material were determined by differential scanning calorimetry (DSC) and thermogravimetric analysis (TGA). Volatile compounds in food samples contained in active packaging systems were monitored by using headspace solid phase microextraction followed by gas chromatography analysis (HS-SPMEGC-MS) at controlled conditions. The obtained results provided evidences that exposure to carvacrol and thymol is an effective way to enlarge the quality of strawberries and bread samples during distribution and sale.
\end{abstract}

Keywords: Active packaging; Carvacrol; Thymol; Strawberries; Bread; Thermal properties; Volatile profile

\section{Introduction}

Active packaging is the one of most relevant approaches to increase the protection and shelf-life of fresh food [1,2]. Active packaging is broad concept that can be defined as a system in which the product, the packaging material and the environment interact in a positive way to extend food shelf-life [3,4]. Many different active agents can be incorporated into the packaging material to improve its functionality. The migration of the active compound may be achieved by direct contact between food and the packaging material or through gas phase diffusion from the inner packaging layer to the food surface [5-8].

Food can be subjected to microbial contamination that is mainly caused by bacteria, yeasts and fungi. Many of these microorganisms can cause undesirable reactions and can deteriorate organoleptic and nutritional properties of foods [9]. Different antimicrobial (AM) agents (most of them synthetic) are commonly incorporated directly into the food to diminish food spoilage by microorganisms. But this strategy has several disadvantages such as: the rising consumer refusal for food with synthetic additives; the useless addition of these agents to the food bulk when spoilage occurs primarily on the surface and the undesirable modification of food flavor. Therefore, antimicrobial packaging is a promising method to protect food from microbial contamination with no need of using synthetic additives in food composition [10].

Natural AM agents (AMs) have attracted much attention from food and packaging industries by their potential action in food preservation. According to Davidson and Zivanovic, natural AM agents can be classified by their sources in vegetal (herbs and essential oils (EOs)), animals (lysozyme, lactoferrin), microbials (nisin, natamycin) or antimicrobial polymers (chitosan) [11]. In these sense, many studies have focused on the AMs present in EOs extracted from plants (basil, thyme, oregano, cinnamon, clove, rosemary) consisting on complex mixtures of different compounds including terpenoids, esters, aldehydes, ketones, acids and alcohols [12]. These plant EOs are volatile liquids characterized by a strong odor [13]. Extracts derived from herbs and EOs contain many natural compounds such as thymol, linalool and carvacrol with a broad AM range against different pathogenic and spoilage microorganisms including Gram-negative [14,15] and Grampositive species [16,17]; as well as against yeast [18] and molds [19]. In general, these additives are considered to be safe and they have been classified as GRAS (Generally Recognized As Safe) by the American Food and Drug Administration [20].

Rodriguez et al. studied the addition of EOs to a wax coating in order to develop an antimicrobial active packaging and they assessed their ability to preserve strawberries from microorganism contamination by the release of AMs from the coating [20]. During this study, there was no direct contact between the EOs and the food product. Therefore, the chemicals responsible for the inhibition of the pathogen growth must have been the natural volatile compounds (eugenol, carvacrol, thymol) present in the headspace packaging. In other study, carvacrol was added to chitosan-based films for active packaging and its antimicrobial efficiency against food spoilage microorganisms was demonstrated by using a headspace chromatographic technique [21]. Gutierrez et al. [22] used a cinnamon-based active material to increase more than three times the shelf-life of a complex bakery product with minimal changes in the packaging and no additional manipulation steps [20].

In addition to microbial contamination, there are changes in the food macroscopic properties that also induced biochemical reactions and chemical alterations in tissues, such as changes in the volatile profile $[23,24]$ and development of undesirable chemicals (i.e. ethanol or acetaldehyde) associated with changes in the respiratory paths [25]. Flavor is one of the main factors influencing consumer's food choice [26]. Volatile compounds are important contributors to flavor and odor of fruits, being aroma a very important quality attribute of strawberries. The flavor of strawberries is comprised of a complex mixture of esters, aldehydes, alcohols, furans and sulfur compounds. Esters are the main headspace volatiles. Methyl esters amount increases

*Corresponding author: Gennady E Zaikov, N.M. Emanuel Institute of Biochemical Physics, Russian Academy of Sciences, 4 Kosygin str. Moscow 119334, Russia E-mail: chembio@sky.chph.ras.ru

Received February 23, 2013; Accepted May 23, 2013; Published May 30, 2013

Citation: Ramos M, Beltran A, Valdes A, Peltzer MA, Jimenez A, et al. (2013) Carvacrol and Thymol for Fresh Food Packaging. J Bioequiv Availab 5: 154-160. doi:10.4172/jbb.1000151

Copyright: $\odot 2013$ Ramos M, et al. This is an open-access article distributed under the terms of the Creative Commons Attribution License, which permits unrestricted use, distribution, and reproduction in any medium, provided the original author and source are credited. 
with the plant maturation, while ethyl esters amount do not change significantly during the fruit growth [27].

In the case of bread, aroma has been largely studied and many methods have been developed to identify the compounds responsible of flavor [28]. More than 540 different compounds have been described in the complex volatile fraction of bread [29], being alcohols, aldehydes, esters, ketones, acids, pyrazines and pyrrolines the most important quantitatively, but furans, hydrocarbons and lactones were also identified [30].

Solid Phase Microextraction (SPME) has become one of the preferred techniques in aroma analysis, offering solvent free, rapid sampling with low cost and easy preparation. Also, it is sensitive, selective and compatible with low detection limits [31]. Placed in the sample headspace, SPME is a non-destructive and non-invasive method to evaluate volatile and semi-volatile compounds. In this sense, the extraction of volatile compounds released from a great number of foods has been carried out by using HS-SPME technique $[30,32]$.

Besides the increasing concern in recent years about the use of synthetic polymers due to their poor biodegradability and high permanence in the environment after their use, these materials are still highly competitive by their many advantages including low cost, good process ability and excellent mechanical and physical properties. Therefore, the development of antimicrobial packaging materials manufactured from synthetic polymers, such as low-density polyethylene (LDPE), high-density polyethylene (HDPE), polystyrene (PS), polyethylene terephthalate (PET) and polypropylene (PP) is important by their commercial benefits for food packaging [10].

This study focuses on the optimization of antifungal active systems based on the controlled release of carvacrol and thymol from polypropylene (PP) films. The effectiveness of the developed active films was evaluated by studying the headspace volatile composition of two food samples (bread and strawberries) stored at different conditions. This study was carried out by headspace Solid Phase MicroExtraction (SPME) followed by gas chromatography analysis (HSSPME-GC-MS). Results were correlated with the antimicrobial activity by visual observation of the fungal growth in the studied food (bread and strawberries). In addition, the effect of the studied additives on the thermal properties of the developed active films was also carried out.

\section{Experimental}

\section{Materials}

The polymer used in this work was polypropylene (PP) ECOLEN HZ10K (Hellenic Petroleum, Greece), kindly supplied in pellets by Ashland Chemical Hispania (Barcelona, Spain). Melt flow index (MFI)

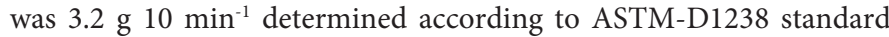
$\left(230^{\circ} \mathrm{C}, 2.16 \mathrm{Kg}\right)$ [33], and density $0.9 \mathrm{~g} \mathrm{~cm}^{-3}$. Carvacrol (98\%) and thymol (99.5\%) were obtained from Sigma-Aldrich (Madrid, Spain).

Strawberries and sliced bread were purchased from a local market. Damaged, non-uniform, unripe or overripe strawberries were removed and the selected fruits were stored for at least $2 \mathrm{~h}$ at $3^{\circ} \mathrm{C}$ to ensure their thermal equilibrium. Strawberries were selected for this study due to their rapid post-harvest deterioration, which constitutes a problem on their commercial distribution. Sliced bread was selected due to the increasing consumer demand for fresh bread with long shelf-life.

\section{Preparation of active films}

Active films were prepared by melt-blending followed by compression molding by using a method previously reported [32]. A Haake Polylab QC mixer (ThermoFischer Scientific, Walham, USA) at $190^{\circ} \mathrm{C}$ for $6 \mathrm{~min}$ at rotation speed of $50 \mathrm{rpm}$ was used. Both additives were introduced in the mixer once the polymer was already in the melt state to avoid unnecessary losses and to ensure their presence in the final materials. The active antimicrobial films were obtained at $190^{\circ} \mathrm{C}$ in a hot press (Carver Inc, Model 3850, USA) for 12 minutes. The average thickness of the films was around $200 \mu \mathrm{m}$ measured with a Digimatic Micrometer Series 293 MDC-Lite (Mitutoyo, Japan) at five random positions around the film. The final appearance of the films was completely transparent and homogenous.

Two active formulations were prepared: PP containing $8 \mathrm{wt} \%$ of thymol (PPT8) and PP with 8 wt\% of carvacrol (PPC8). An additional sample without any active compound was also prepared and used as control (PP0) [33].

\section{Thermal characterization of active films}

Thermogravimetric analysis (TGA): TGA tests were performed in a TGA/SDTA 851 Mettler Toledo thermal analyzer (Schwarzenbach, Switzerland). Approximately $5 \mathrm{mg}$ samples were weighed in alumina pans $(70 \mu \mathrm{L})$ and were heated from $30^{\circ} \mathrm{C}$ to $700^{\circ} \mathrm{C}$ at a heating rate of $10^{\circ} \mathrm{C} \mathrm{m^{-1 }}$ under inert nitrogen atmosphere (flow rate $50 \mathrm{~mL} \mathrm{~min}^{-1}$ ).

\section{Differential scanning calorimetry (DSC):}

Determination of thermal parameters in inert atmosphere: DSC tests were conducted in a TA DSC Q-2000 instrument (New Castle, DE, USA) under inert nitrogen atmosphere. $3 \mathrm{mg}$ samples were introduced in aluminium pans $(40 \mu \mathrm{L})$ and were submitted to the following thermal program: heating from $0^{\circ} \mathrm{C}$ to $180^{\circ} \mathrm{C}$ at $10^{\circ} \mathrm{C} \mathrm{min}{ }^{-1}$ (3 min hold), cooling at $10^{\circ} \mathrm{C} \mathrm{min}^{-1}$ to $0^{\circ} \mathrm{C}$ ( $3 \mathrm{~min}$ hold) and heating to $180^{\circ} \mathrm{C}$ at $10^{\circ} \mathrm{C} \mathrm{m^{-1 }}$. The percentage of crystallinity ( $\left.\chi \%\right)$ for each material was calculated according to the following equation,

$$
\chi(\%)=\left(\Delta H_{m} / W \Delta H_{m}^{o}\right) \cdot 100
$$

where $\Delta H_{m}\left(\mathrm{~J} \mathrm{~g}^{-1}\right)$ is the latent heat of fusion of the sample, $W$ is the PP weight fraction in the sample, and $\Delta H_{m}{ }^{\circ}$ is the theoretical latent heat of fusion for $100 \%$ crystalline PP, $138 \mathrm{~J} \mathrm{~g}^{-1}$ [34].

Evaluation of oxidation induction time: The antioxidant performance of carvacrol and thymol in the developed active films was also studied by DSC by determining their oxidation induction time, OIT ( $\mathrm{min})$. The OIT value is defined as the time to the onset of an exothermic oxidation peak in oxidative atmosphere and it was determined by using oxygen and air, as the results obtained can be dependent on the type of atmosphere used for the analysis.

OIT tests were carried out by heating samples at $100^{\circ} \mathrm{C} \mathrm{min}^{-1}$ under nitrogen (flow rate $\left.50 \mathrm{~mL} \mathrm{~min}^{-1}\right)$ to the set temperature $\left(200^{\circ} \mathrm{C}\right.$ ) according to ASTM-D3895-07 Standard. After $5 \mathrm{~min}$, the atmosphere was switched to pure oxygen or air $\left(50 \mathrm{~mL} \mathrm{~min}^{-1}\right)$. The heat flow was then recorded in isothermal conditions up to the detection of the exothermic peak indicating the beginning of the oxidation reaction. All tests were performed in triplicate for each formulation.

\section{Study of the effectiveness of the active films to preserve perishable food}

Observation of fungal growth: The effectiveness of the developed active films was evaluated by putting them in contact with sliced bread and strawberries and further observing the occurrence of fungal growth on food samples with time. For this purpose, food samples were 
appropriately cut to be placed on the base of disposable polypropylene Petri dishes (inside dimensions: $88 \mathrm{~mm}$ diameter $\times 12 \mathrm{~mm}$ high). An additional test was carried out with uncut strawberries which were placed into a polyethylene suitable food container $(250 \mathrm{~mL}, 4 \mathrm{~cm}$ high $\times 13 \mathrm{~cm}$ opening diameter) as shown in Figure 1 .

Active films were cut with the appropriate dimensions to match the top of the lid of the used containers in order to release the antimicrobial studied agents (carvacrol and thymol) into the packaging headspace. The final containers were then sealed with "Parafilm" in order to avoid losses of volatile compounds and were incubated at $25^{\circ} \mathrm{C}$ and $50 \% \mathrm{RH}$ in a CM 0/81 climatic chamber (Dycometal, Barcelona, Spain) during 15 days. Food samples stored with the control film (without active compounds) were also studied for comparison.

Headspace analysis by HS-SPME-GC-MS: Food samples (whole strawberries and sliced bread) were placed into the polyethylene container described in the previous section in direct contact with the PP films and samples were extracted at selected times to determine the headspace composition. Containers were sealed and a PTFE/ silicone septum was placed on their top part to allow the insertion of the SPME fibre for volatiles extraction (Figure 1). Samples were then stored in a climatic chamber and tested at different temperatures and days of storage according to the conditions shown in Table 1. In this sense, $25^{\circ} \mathrm{C}$ and $4^{\circ} \mathrm{C}$ were selected in order to simulate ambient and refrigerated storage conditions, respectively. Three replicates were performed for each food sample and day of study.

HS-SPME analysis of volatile compounds for food samples was performed according to a previously reported method applied to bread samples [35] with slight modifications. Similar conditions to those proposed by G. Blanda et al. were used in the study with strawberries [36]. The SPME fibre used was divinylbenzene/carboxen/ polydimethylsiloxane (DVB/CAR/PDMS) 50/30 $\mu \mathrm{m}$, StableFlex, 1 $\mathrm{cm}$ long mounted to an SPME manual holder assembly from Supelco (Bellefonte, PA) (Figure 1). Prior to use, the fibre was conditioned by following the manufacturer's recommendations. The needle of the SPME device was inserted into the container through the septum and the fibre was exposed to the food sample headspace for $30 \mathrm{~min}$ at room temperature. The fibre was then retracted into the needle assembly, removed from the container, transferred to the injection port of the GC unit and immediately desorbed.

Analysis of volatiles produced in the headspace of bread and strawberries packed samples was performed by using a Perkin Elmer TurboMass Gold GC-MS (Boston, MA, USA) equipped with a split/ splitless injector and a quadrupole mass spectrometer operating in electronic impact (EI) ionisation mode $(70 \mathrm{eV})$. A SPB-5 capillary column (30 m×0.25 mm $\times 0.25 \mu \mathrm{m}$; Supelco, Bellefonte, PA, USA) was

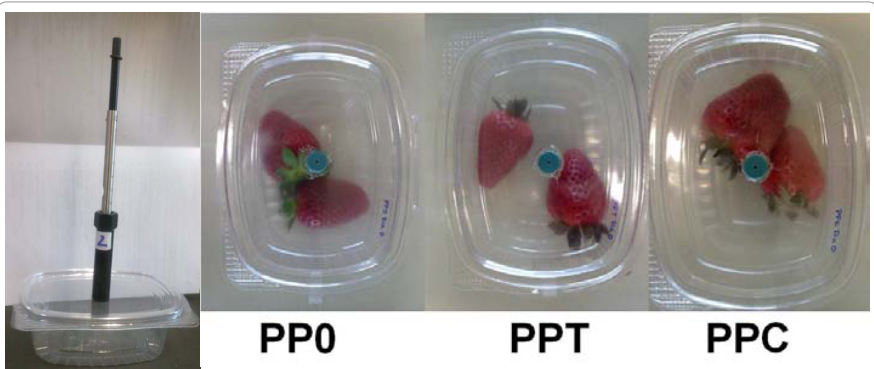

Figure 1: Experimental assembly used for headspace analysis of whole strawberries by HS-SPME.

\begin{tabular}{|l|c|c|c|c|c|c|c|}
\hline Food sample & Temperature $\left({ }^{\circ} \mathbf{C}\right)$ & \multicolumn{5}{|c|}{ Days of study } \\
\hline Slice bread & 25 & 0 & 2 & 5 & 10 & 15 & - \\
\hline Whole strawberries & 25 & 0 & 2 & 4 & 7 & 10 & - \\
\hline Whole strawberries & 4 & 0 & 2 & 4 & 7 & 10 & 15 \\
\hline
\end{tabular}

Table 1: Storage and testing conditions in the headspace study of food by HSSPME-GC-MS.

used. The column temperature was programmed from $40^{\circ} \mathrm{C}$ (hold $10 \mathrm{~min}$ ) to $120^{\circ} \mathrm{C}$ (hold $1 \mathrm{~min}$ ) at $5^{\circ} \mathrm{C} \mathrm{min}^{-1}$, to $140^{\circ} \mathrm{C}$ at $2^{\circ} \mathrm{C} \mathrm{min}$ ${ }^{1}$ (hold $0 \mathrm{~min}$ ) and to $230^{\circ} \mathrm{C}$ at $5^{\circ} \mathrm{C} \mathrm{min}^{-1}$ (hold $8 \mathrm{~min}$ ). Helium was used as carrier gas at a flow rate of $1 \mathrm{~mL} \mathrm{~min}^{-1}$. Ion source and GC/MS transfer line temperatures were 250 and $270^{\circ} \mathrm{C}$, respectively. Injector temperature was $270^{\circ} \mathrm{C}$ and time for fibre desorption was fixed at 5 min in the splitless mode (1.5 min splitless-period). After every run, the SPME fibre was conditioned for $30 \mathrm{~min}$ at $270^{\circ} \mathrm{C}$ in the injector of the gas chromatograph followed by a blank analysis to avoid carryover of the fibre.

Identification of volatile compounds in strawberries and sliced bread headspace was performed in full scan mode (m/z 30-550). Carvacrol and thymol were identified by a combination of the NIST mass spectral library and gas chromatographic retention times of standard compounds. The rest of volatiles were tentatively identified by their GC/MS spectra. In this sense, the compounds having $\leq$ $90 \%$ similarity with spectra in the NIST library were not taken into consideration. Chromatographic responses of detected volatile compounds (peak area counts) were monitored for comparative measurements of each compound in the studied samples.

\section{Results and Discussion}

\section{Thermogravimetric analysis (TGA)}

The effect of carvacrol and thymol on the thermal stability of PP films was studied by TGA under nitrogen atmosphere. The TGA patterns obtained for PP films showed a first degradation step at low temperatures (about $115^{\circ} \mathrm{C}$ ) observed only for active films, which was associated to the thermal decomposition of carvacrol and/or thymol and a second step corresponding to the thermal degradation of the polymer matrix [34]. The first degradation step observed for active films was considered as an indirect confirmation of the presence of the active compounds (thymol and carvacrol) in the polymer matrix after processing and consequently their ability to act as active agents in these materials as it has been reported by other authors [36].

Table 2 summarizes the temperatures obtained for the main degradation step $\left(\mathrm{T}_{\max }\right)$, ascribed to the PP thermal degradation. No significant differences were observed for $\mathrm{T}_{\max }$ values in all samples. These results showed that the addition of carvacrol and thymol to the polymer matrix did not significantly affect its thermal degradation profile in inert nitrogen atmosphere. However, it would be expectable that a certain amount of carvacrol and thymol would be lost during processing, since materials are submitted to temperatures above the decomposition point of these additives. Therefore, the processing parameters, in particular temperature and time, should be optimized to avoid the excessive evaporation and consequent loss of these additives incorporated to PP [37].

\section{Differential Scanning Calorimetry (DSC)}

Determination of thermal parameters in inert atmosphere:

Four parameters were determined for the thermal 


\begin{tabular}{|c|c|c|c|c|c|c|c|c|}
\hline Sample & $\begin{array}{l}T_{\max } \\
\left({ }^{\circ} \mathrm{C}\right)\end{array}$ & $\begin{array}{l}\mathrm{T}_{\mathrm{c}} \\
\left({ }^{\circ} \mathrm{C}\right)\end{array}$ & $\begin{array}{l}\mathrm{T}_{\mathrm{m}} \\
\left({ }^{\circ} \mathrm{C}\right)\end{array}$ & $\begin{array}{l}\Delta \mathrm{H}_{\mathrm{c}} \\
\left(\mathrm{J} \mathrm{g}^{-1}\right)\end{array}$ & $\underset{\left(\mathrm{J} \mathrm{g}^{-1}\right)}{\Delta \mathrm{H}_{\mathrm{m}}}$ & $\begin{array}{c}X \\
(\%)\end{array}$ & $\begin{array}{c}\text { OIT } \\
(\min ) \text { Oxygen }\end{array}$ & $\begin{array}{c}\text { OIT } \\
(\min ) \text { Air }^{\mathrm{a}}\end{array}$ \\
\hline PPO & 461 & 119 & 161 & 95.2 & 99.1 & 72 & $0.9 \pm 0.3$ & $1.3 \pm 0.4$ \\
\hline PPC8 & 462 & 118 & 161 & 89.2 & 48.1 & 38 & $8.5 \pm 1.0$ & $20.7 \pm 2.8$ \\
\hline РРТ8 & 462 & 115 & 159 & 88.9 & 49.5 & 39 & $15.4 \pm 1.7$ & $38.8 \pm 0.6$ \\
\hline
\end{tabular}

amean $\pm S D(n=3)$

Table 2: TGA, DSC and OIT parameters obtained for all samples.

caharacterization of these materials by DSC (Table 2): coldcrystallization temperature, $\mathrm{T}_{c c}\left({ }^{\circ} \mathrm{C}\right)$; melting temperature, $\mathrm{T}_{\mathrm{m}}\left({ }^{\circ} \mathrm{C}\right)$; crystallization enthalpy, $\Delta \mathrm{H}_{\mathrm{c}}\left(\mathrm{Jg}^{\mathrm{cc}}\right)$ and melting enthalpy, $\Delta \mathrm{H}_{\mathrm{m}}\left(\mathrm{Jg}^{-1}\right)$. As can be seen in Table 2, melting and cold-crystallization temperatures as well as crystallization enthalpy did not show important differences for all the studied materials. Nevertheless, it should be highlighted that the melting enthalpy of PP0 sample was clearly higher than those obtained for the active materials. In this sense, crystallinity, $\chi(\%)$, of samples was calculated according to equation (1) to evaluate if the addition of thymol and carvacrol could alter the crystallization behavior of PP. A higher value for $\chi(\%)$ was determined for the PP0 sample. Therefore, it could be concluded that the PP crystallinity decreases significantly with the addition of thymol and carvacrol. This decrease in crystallinity could be due to the interactions between the polymer matrix and the additive molecules in the PP macromolecular network. A similar effect was reported for PP with the addition of some commercial synthetic antioxidants, such as Irgafos 168 and Irganox 1010 [38].

Evaluation of the oxidation induction time (OIT): The determination of OIT is considered a simple, reliable and fast method for the evaluation of the antioxidants efficiency [39], corresponding to relative measurements of the materials stability against oxidation. The evaluation of the antioxidant performance of carvacrol and thymol in PP is important since they are supposed not only to play the role of active additives for food, but also to protect the polymer to oxidative degradation during processing and use.

The evaluation of OIT was carried out in two different atmospheres. Air was selected to get a similar situation to the real conditions during materials processing or food shelf-life, while the use of pure oxygen would represent the most aggressive conditions for oxidative degradation. Table 2 shows the results obtained for OIT in both atmospheres.

In both cases it was confirmed the higher efficiency of thymol as an antioxidant when compared to carvacrol. This behavior was also reported by other authors who demonstrated that the antioxidant efficiency of thymol was higher in sunflower oil samples [40]. In the case of air atmosphere, as expected, OIT values were higher than those obtained in pure oxygen atmosphere, since the experiment under air is less aggressive to materials [41].

In all cases, the increase in OIT values for PP with additives showed the existence of certain antioxidant effect after processing. These results are an additional confirmation that certain amounts of thymol and carvacrol are still remaining in all formulations after processing and they would be able to be released from the material to foodstuff as active additives.

\section{Study of the effectiveness of the active films to preserve perishable food}

Observation of fungal growth: This study was conducted to evaluate the antimicrobial activity of the developed films and their ability to act in active packaging formulations to increase the fresh food shelf-life. It was based on the visual observation of the inhibition of the fungal growth on food samples by the action of the volatile active additives, carvacrol and thymol. In this sense, some studies by other authors showed the effectiveness of these compounds against different fungal strains of particular interest in the food industry [14].

Figure 2 shows the appearance of sliced strawberries and bread samples at the beginning of the experiment (day 0) and after the observation of microbial growth. Regarding strawberries, satisfactory results were obtained for samples in contact with the films with additives, since no fungal growth was observed until six days of storage. In the case of strawberries in contact with the pure PP film (PP0), a rapid growth of microorganisms was observed at the third day of treatment.

On the other hand, the presence of microorganisms was observed in bread samples in contact with the PP0 film after 13 days of storage, in contrast with bread with the films with additives where no evidence of microbial contamination after 45 days of storage was observed.

However, it was noticed that strawberries lost their organoleptic properties in a few days, even before the visual evidence of fungal growth, when they were cut and stored. For this reason this study was also conducted for uncut strawberries (Figure 3). For the PP0 film microbial growth was observed after 6 days of storage. However, strawberries in contact with the film containing $8 \mathrm{wt} \%$ of thymol (PPT8) remained unaltered after 13 days. At this storage time strawberries presented a physical deterioration due to the experimental storage

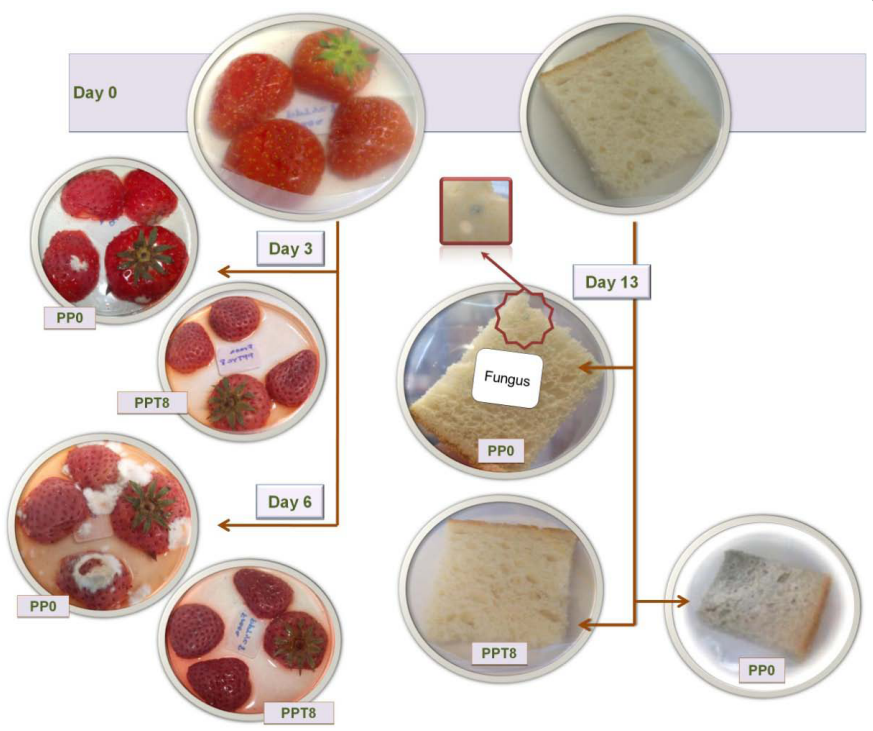

Figure 2: Study of the effectiveness of PPO and active films containing 8 wt $\%$ of thymol (PPT8) to preserve cut bread and strawberries by observation of fungal growth. 
conditions, but it is important to highlight that microbial growth was not observed until the end of the study (15 days).

Similar studies were performed with uncut strawberries by other authors, getting satisfactory results for samples in contact with films treated with essential oils, such as cinnamon, oregano and thyme [20]. Regarding thyme and oregano essential oils, their antimicrobial activity is due to the high amount of carvacrol and thymol in their composition $[42,43]$. Other studies conducted in different fruits and vegetables also demonstrated the effectiveness of the constituents of different essential oils (eugenol, thymol, menthol or eucalyptol) to improve the organoleptic quality of food as well as to reduce the microbial growth, by using also a modified atmosphere [8].

In conclusion, results obtained from food samples in contact with PP films containing carvacrol and thymol evidenced the effectiveness of these compounds to improve the shelf-life of perishable food, such as strawberries and bread. Accordingly, these results also indicated the potential to use the developed films in active packaging systems to replace the direct addition of preservatives in food formulations.

Headspace analysis by HS-SPME-GC-MS: Figure 4 shows the levels of carvacrol, in terms of peak area counts, reached in the headspace of the containers with bread slices after $0,2,5,10$ and 15 days of storage at room temperature. As it can be seen, an increase in the amount of carvacrol released from the PP films was observed with time for the bread samples. A high release of carvacrol was observed at 2 days, being released more slowly after 5, 10 and 15 days of storage. This mechanism of controlled release could lead to shelf-life improvement of the stored samples retarding the post-harvest deterioration. This behavior was also observed for strawberries. Regarding the thymol release, a similar trend was shown for both test food samples.

Equilibrium modified atmosphere packaging (EMAP) is the most commonly used packaging technology to reduce the high respiration rate of strawberries. It is known that a suitable atmosphere composition can reduce the respiration rate of fruits and fungal growth with minimal alteration of organoleptic properties [26]. In this sense, Table

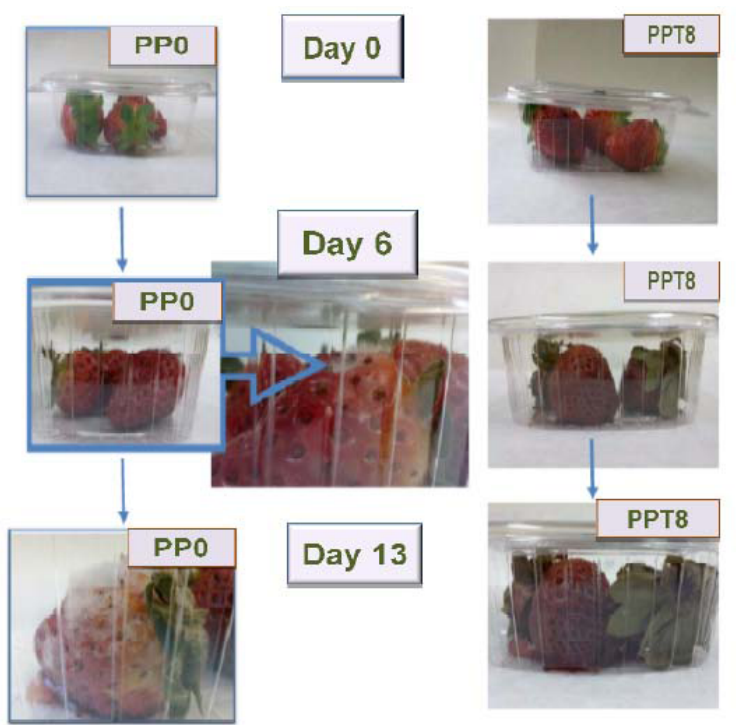

Figure 3: Evaluation of the effectiveness of PPO and active film containing $8 \mathrm{wt} \%$ of thymol (PPT8) to preserve uncut strawberries by observation of fungal growth.
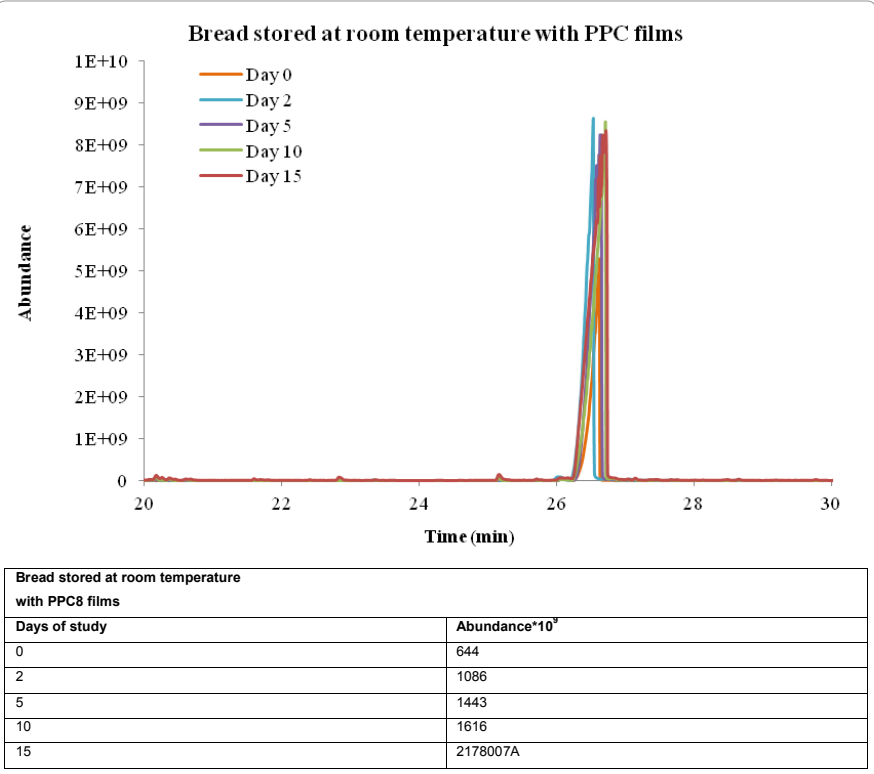

Figure 4: Release of carvacrol in the headspace of bread slices after 0, 2, 5 , 10 and 15 days of storage at room temperature.

3 shows the compounds identified in the headspace of strawberries with PP0 films after 4 days. One of the most important processes occurring during fruit ripening is the increase in volatiles contributing to fruit aroma and flavor. The major volatiles identified for strawberries stored at room temperature include methyl-isopentanoate, 2-methylbutylacetate, methyl-hexanoate and hexyl-acetate. The compounds methyl-butanoate and methyl-hexanoate were also found in the headspace composition of refrigerated strawberries at $4^{\circ} \mathrm{C}$. These results are in accordance with those obtained by other authors when studying volatile compounds in the same food samples [26,27].

The addition of thymol and carvacrol to PP films significantly modified the initial atmosphere composition inside packages during the storage of food samples due to their release from the film. This fact could be related to the inhibition of the volatile identified compounds (Table 3) that did not were detected in samples in contact with PPT8 and PPC8 films after 4 days of storage.

On the other hand, ethanol was the main volatile found in the headspace of bread in contact with the PP0 film and stored at room temperature for 4 days. This compound was resulting from fermentation and/or lipid oxidation as it has been reported by other authors [29]. In this sense, commercial bread samples in contact with PPT8 or PPC8 films after 4 days of storage were characterized by significantly lower amounts of ethanol, suggesting a reduction on the lipid oxidation reactions by the presence of thymol and carvacrol. The improvement on the oxidative stability of bread could be attributed to the release of carvacrol and thymol increasing the shelf-life of bread.

From these results, it can be concluded that the release of both additives from active films to the headspace of the studied packaged foodstuff increased with the storage time, as expected. The volatiles profile obtained by HS-SPME-GC-MS was found to be different for samples in contact with PP0 and those with PPT8 and PPC8, due to the modification of the food headspace composition by the presence of these additives. Therefore, the release of thymol and carvacrol from the active PP films has shown to be effective in maintaining the quality 
Citation: Ramos M, Beltran A, Valdes A, Peltzer MA, Jimenez A, et al. (2013) Carvacrol and Thymol for Fresh Food Packaging. J Bioequiv Availab 5: 154-160. doi:10.4172/jbb.1000151

\begin{tabular}{|c|c|c|c|c|c|}
\hline \multicolumn{2}{|c|}{$\begin{array}{l}\text { Bread stored } \\
\text { at room temperature }\end{array}$} & \multicolumn{2}{|c|}{$\begin{array}{l}\text { Strawberries stored } \\
\text { at room temperature }\end{array}$} & \multicolumn{2}{|c|}{$\begin{array}{l}\text { Strawberries } \\
\text { refrigerated at } 4^{\circ} \mathrm{C}\end{array}$} \\
\hline $\begin{array}{l}\text { Time } \\
(\min )\end{array}$ & Compound & $\begin{array}{l}\text { Time } \\
(\min )\end{array}$ & Compound & $\begin{array}{l}\text { Time } \\
(\min )\end{array}$ & Compound \\
\hline 1.4 & Ethanol & 3.2 & Methyl isopentanoate & 1.9 & Hexane \\
\hline 5.7 & 2,4-dimethylheptane & 5.8 & 2-methyl butylacetate & 3.1 & Methylbutanoate \\
\hline 6.6 & 2,4-dimethyl heptene & 7.4 & Methyl hexanoate & 3.9 & Toluene \\
\hline 7.8 & Isononane & 10.6 & Hexylacetate & 6.8 & Isopropyl butyrate \\
\hline 13.0 & 4-methyloctane & & & 12.2 & Methyl hexanoate \\
\hline
\end{tabular}

Table 3: Identified compounds present in the headspace of food samples packed with PP0 films after 4 days.

of strawberries and bread during different storage conditions. Finally, it can be concluded that PP films with carvacrol and thymol could be a promising alternative to increase the shelf-life of different foodstuff.

\section{Conclusions}

Carvacrol and thymol have demonstrated their potential to be used as active additives in PP films for food packaging applications by their controlled antimicrobial release to foodstuff and also by the possibility to protect food from degradation processes. The addition of carvacrol and thymol did not significantly affect the thermal behavior of PP, but they modified the material cristallinity. PP films containing carvacrol and thymol showed a significant increase in OIT values, indicating that the polymer is well stabilized and a certain amount of these compounds remained in the polymer matrix after processing at relatively high temperatures. In this sense, these additives could be furthermore released from the material playing their role as antimicrobial additives. Therefore, it could be concluded that the addition of antimicrobial additives as carvacrol and thymol at $8 \mathrm{wt} \%$ to $\mathrm{PP}$ shows potential to improve the food quality and safety.

\section{Acknowledgments}

Authors would like to thank Ashland Chemical Hispania for kindly supplying ECOLEN HZ10K PP (Hellenic Petroleum). Marina Ramos would like to thank University of Alicante (Spain) for UAFPU2011-48539721S predoctoral research grant.

\section{References}

1. Dong SL, Luciano Piergiovanni KLY (2008) Food packaging science and technology. Boca Raton: CRC Press.

2. Singh $P$, Wani $A A$, Saengerlaub $S$ (2011) Active packaging of food products: Recent trends. Nutrition and Food Science 41: 249-260.

3. Cutter CN (2002) Microbial control by packaging: a review. Crit Rev Food Sci Nutr 42: 151-161.

4. Mastromatteo M, Mastromatteo M, Conte A, Del Nobile MA (2010) Advances in controlled release devices for food packaging applications. Trends in Food Science \& Technology 21: 591-598.

5. Coma V (2008) Bioactive packaging technologies for extended shelf life of meat-based products. Meat Sci 78: 90-103.

6. Conte A, Buonocore GG, Bevilacqua A, Sinigaglia M, Del Nobile MA (2006) Immobilization of lysozyme on polyvinylalcohol films for active packaging applications. J Food Prot 69: 866-870.

7. Gemili S, Yemenicioglu A, Altinkaya SA (2009) Development of cellulose acetate based antimicrobial food packaging materials for controlled release of lysozyme. Journal of Food Engineering 90: 453-462.

8. Mastromatteo M, Conte A, Del Nobile M (2010) Combined use of modified atmosphere packaging and natural compounds for food preservation. Food Engineering Reviews 2: 28-38.

9. Kuorwel KK, Cran MJ, Sonneveld K, Miltz J, Bigger SW (2011) Antimicrobial Activity of Natural Agents against Saccharomyces cerevisiae. Packaging Technology and Science 24: 299-307.
10. Kuorwel KK, Cran MJ, Sonneveld K, Miltz J, Bigger SW (2011) Essential oils and their principal constituents as antimicrobial agents for synthetic packaging films. J Food Sci 76: R164-177.

11. Davidson PM ZS (2003) The use of natural antimicrobials. Food preservation techniques. Boca Raton, Fla.: Woodhead Publishing Limited and CRC Press.

12. Dorman HJ, Deans SG (2000) Antimicrobial agents from plants: antibacterial activity of plant volatile oils. J Appl Microbiol 88: 308-316.

13. Bakkali F, Averbeck S, Averbeck D, Idaomar M (2008) Biological effects of essential oils--a review. Food Chem Toxicol 46: 446-475.

14. Lopez P, Sanchez C, Batlle R, Neren C (2007) Development of flexible antimicrobial films using essential oils as active agents. J Agric Food Chem 55: 8814-8824.

15. Suppakul P, Sonneveld K, Bigger SW, Miltz J (2011) Diffusion of linalool and methylchavicol from polyethylene-based antimicrobial packaging films. LWT Food Science and Technology 44: 1888-1893.

16. Gutiérrez L, Sánchez C, Batlle R, Nerín C (2009) New antimicrobial active package for bakery products. Trends in Food Science \& Technology 20: 92-99.

17. Lopez P, Sanchez C, Batlle R, Neren C (2007) Vapor-phase activities of cinnamon, thyme, and oregano essential oils and key constituents agains foodborne microorganisms. J Agric Food Chem 55: 4348-4356.

18. Kuorwel KK, Cran MJ, Sonneveld K, Miltz J, Bigger SW (2013) Migration of antimicrobial agents from starch-based films into a food simulant. LWT - Food Science and Technology 50: 432-438.

19. Rodriguez-Lafuente A, Nerin C, Batlle R (2010) Active paraffin-based paper packaging for extending the shelf life of cherry tomatoes. J Agric Food Chem 58: $6780-6786$.

20. Rodríguez A, Batlle R, Nerín C (2007) The use of natural essential oils as antimicrobial solutions in paper packaging. Part II. Progress in Organic Coatings 60: 33-38.

21. Kurek M, Moundanga S, Favier C, Galic K, Debeaufort F (2013) Antimicrobia efficiency of carvacrol vapour related to mass partition coefficient when incorporated in chitosan based films aimed for active packaging. Food Control 32: $168-175$.

22. Gutie'rrez L, Escudero A, Batlle Rn, Neri'n C (2009) Effect of Mixed Antimicrobia Agents and Flavors in Active Packaging Films. Journal of Agricultural and Food Chemistry 57: 8564-8571.

23. Chiralt A, Marti'nez-Navarrete N, Marti'nez-Monzó J, Talens P, Moraga G, et al. (2001) Changes in mechanical properties throughout osmotic processes: Cryoprotectant effect. Journal of Food Engineering 49: 129-135.

24. Tovar Bz, Garci'a HS, Mata M (2001) Physiology of pre-cut mango. I. ACC and ACC oxidase activity of slices subjected to osmotic dehydration. Food Research International 34: 207-215.

25. Pozo-Bayón MA, Guichard E, Cayot N (2006) Flavor Control in Baked Cereal Products. Food Reviews International 22: 335-379.

26. Rizzolo A, Gerli F, Prinzivalli C, Buratti S, Torreggiani D (2007) Headspace volatile compounds during osmotic dehydration of strawberries (cv Camarosa): Influence of osmotic solution composition and processing time. LWT - Food Science and Technology 40: 529-535.

27. Cayot N (2007) Sensory quality of traditional foods. Food Chemistry 101: 154 162 
Citation: Ramos M, Beltran A, Valdes A, Peltzer MA, Jimenez A, et al. (2013) Carvacrol and Thymol for Fresh Food Packaging. J Bioequiv Availab 5: 154-160. doi:10.4172/jbb.1000151

28. Ruiz JA, Quilez J, Mestres M, Guasch J (2003) Solid-Phase Microextraction Method for Headspace Analysis of Volatile Compounds in Bread Crumb. Cereal Chemistry Journal 80: 255-259.

29. Poinot P, Arvisenet G, Grua-Priol J, Colas D, Fillonneau C, et al. (2008) Influence of formulation and process on the aromatic profile and physical characteristics of bread. Journal of Cereal Science 48: 686-697.

30. Ho CW, Wan Aida WM, Maskat MY, Osman H (2006) Optimization of headspace solid phase microextraction (HS-SPME) for gas chromatography mass spectrometry (GC-MS) analysis of aroma compound in palm sugar (Arenga pinnata). Journal of Food Composition and Analysis 19: 822-830.

31. Quílez J, Ruiz JA, Romero MP (2006) Relationships between Sensory Flavor Evaluation and Volatile and Nonvolatile Compounds in Commercial Wheat Bread Type Baguette. Journal of Food Science 71: S423-S427.

32. Ramos M, Jiménez A, Peltzer M, Garrigós MC (2012) Characterization and antimicrobial activity studies of polypropylene films with carvacrol and thymol for active packaging. Journal of Food Engineering 109: 513-519.

33. (2007) ASTM D 3895 - 07 Standard test method for oxidative-induction time of polyolefins by differential scanning calorimetry. In: Annual book of ASTM standards. Amer Soc for Testing \& Materials, Philadelphia, PA.

34. Joseph PV, Joseph K, Thomas S, Pillai CKS, Prasad VS, et al. (2003) The thermal and crystallisation studies of short sisal fibre reinforced polypropylene composites. Composites Part A: Applied Science and Manufacturing 34: 253266.

35. Poinot P, Grua-Priol J, Arvisenet G, Rannou C, Semenou M, Bail AL, et al. (2007) Optimization of HS-SPME to study representativeness of partially baked bread odorant extracts. Food Research International 40: 1170-1184.
36. Persico P, Ambrogi V, Carfagna C, Cerruti P, Ferrocino I, et al. (2009) Nanocomposite polymer films containing carvacrol for antimicrobial active packaging. Polymer Engineering \& Science 49: 1447-1455.

37. Blanda G, Cerretani L, Cardinali A, Barbieri S, Bendini A, et al. (2009) Osmotic dehydrofreezing of strawberries: Polyphenolic content, volatile profile and consumer acceptance. LWT - Food Science and Technology 42: 30-36.

38. Dobkowski Z (2006) Thermal analysis techniques for characterization of polymer materials. Polymer Degradation and Stability 91: 488-493.

39. Alin J, Hakkarainen M (2010) Type of polypropylene material significantly influences the migration of antioxidants from polymer packaging to food simulants during microwave heating. Journal of Applied Polymer Science 118 1084-1093.

40. Pomerantsev AL, Rodionova OY (2005) Hard and soft methods for prediction of antioxidants' activity based on the DSC measurements. Chemometrics and Intelligent Laboratory Systems 79: 73-83.

41. Yanishlieva NV, Marinova EM, Gordon MH, Raneva VG (1999) Antioxidant activity and mechanism of action of thymol and carvacrol in two lipid systems. Food Chemistry 64: 59-66.

42. Riga A, Collins R, Mlachak G (1998) Oxidative behavior of polymers by thermogravimetric analysis, differential thermal analysis and pressure differential scanning calorimetry. Thermochimica Acta 324: 135-149.

43. Hazzit M, Baaliouamer A, Faleiro ML, Miguel MG (2006) Composition of the essential oils of Thymus and Origanum species from Algeria and their antioxidant and antimicrobial activities. J Agric Food Chem 54: 6314-6321. 